\title{
Solution-processed lead-free double perovskite microplatelets with enhanced photoresponse and thermal stability
}

\author{
Zhengxun Lai ${ }^{1}$, Fei Wang ${ }^{1,2,3}$, You Meng ${ }^{1}$, Xiuming Bu ${ }^{1}$, Xiaolin Kang ${ }^{1}$, Quan Quan ${ }^{1}$, Wei Wang ${ }^{1}$, \\ SenPo Yip ${ }^{4}$, Chuntai Liu ${ }^{5}$ and Johnny C. Ho ${ }^{1,3,4^{*}}$
}

\begin{abstract}
Due to the better stability and environmentfriendly nature, lead-free halide double perovskites are widely explored as promising materials for next-generation photovoltaics and optoelectronics; however, to date, their photoelectric device performance is still not satisfactory. Herein, we report a facile solution-process method to synthesize the recently most popular lead-free halide double perovskite, $\mathrm{MA}_{2} \mathrm{AgBiBr}_{6}$, and its all-inorganic counterpart, $\mathrm{Cs}_{2} \mathrm{AgBiBr}_{6}$. The obtained $\mathrm{MA}_{2} \mathrm{AgBiBr}_{6}$ and $\mathrm{Cs}_{2} \mathrm{AgBiBr}_{6}$ films exhibit the microplatelet morphology with excellent crystallinity, distinctly contrasting the ones fabricated by the conventional spin-coating method. Once fabricated into simple photodetectors, the $\mathrm{Cs}_{2} \mathrm{AgBiBr}_{6}$ microplatelet devices yield a respectable responsivity of $245 \mathrm{~mA} \mathrm{~W}^{-1}$ that is two orders of magnitude larger than that of the spin-coated films. More importantly, the response speed of the $\mathrm{Cs}_{2} \mathrm{AgBiBr}_{6}$ microplatelets device is as fast as $145 \mu \mathrm{s}$, which is higher than most of the values reported in the community of halide double perovskites. When subjected to the thermal stability testing, the $\mathrm{Cs}_{2} \mathrm{AgBiBr}_{6}$ microplatelet device can maintain its initial performance after heating to $160^{\circ} \mathrm{C}$ and cooling down to room temperature in the ambient environment. All these results suggest that the facile solution-process method is capable of fabricating high-quality lead-free double perovskites, enabling their advanced device applications.
\end{abstract}

Keywords: lead-free double perovskite, $\mathrm{Cs}_{2} \mathrm{AgBiBr}_{6}$, $\mathrm{MA}_{2} \mathrm{AgBiBr}_{6}$, thermal stability, photodetector

\section{INTRODUCTION}

In recent years, lead halide perovskites have been in the fervent study worldwide due to their fascinating properties for highperformance solar cells, photodetectors and light-emitting diodes $[1,2]$. For instance, the power conversion efficiency of organic-inorganic lead halide perovskites (OIHPs)-based solar cells have been approaching that of single-crystalline silicon solar cells $[3,4]$. Despite of the fruitful achievement of OIHPsbased optoelectronic devices, their practical utilization still seems to be at an unreachable distance. One of the main reasons is that the lead halide perovskites with excellent photoelectric properties are typically toxic, which will induce significant environmental pollution in future large-scale applications. In this regard, non-toxic lead-free halide perovskites are in urgent need.

Technically, the structure of OIHPs can be referred as $\mathrm{ABX}_{3}$, where A represents the organic cations of methylamine $\left(\mathrm{MA}^{+}\right)$ or formamidine $\left(\mathrm{FA}^{+}\right), \mathrm{B}$ is usually occupied by $\mathrm{Pb}^{2+}$, and $\mathrm{X}$ represents the halide ions of $\mathrm{I}^{-}, \mathrm{Br}^{-}$or $\mathrm{Cl}^{-}$. This way, $\mathrm{Sn}^{2+}$ - and $\mathrm{Ge}^{2+}$-based perovskites, which are in the same periodic group as $\mathrm{Pb}^{2+}$, are then expected to be a good alternative for the constituent of $\mathrm{Pb}$. However, the $\mathrm{Sn}^{2+}$ - and $\mathrm{Ge}^{2+}$-based perovskites are easily oxidized in ambient, which makes them with very poor stability for applications [5,6]. Apart from $\mathrm{Sn}^{2+}$ and $\mathrm{Ge}^{2+}$, the non-toxic $\mathrm{Bi}^{3+}$ has also been proposed to replace $\mathrm{Pb}^{2+}$. Unfortunately, $\mathrm{Bi}^{3+}$ cannot support the conventional structure of OIHPs (i.e., $\mathrm{ABX}_{3}$ ). In order to cope with this issue, a new type of perovskite, known as double perovskites, with the formula of $\mathrm{A}_{2} \mathrm{~B}^{\prime} \mathrm{BX}_{6}$ was introduced, as shown in Fig. 1a. In this structure, $\mathrm{B}$ represents a trivalent cation of $\mathrm{Bi}^{3+}, \mathrm{Sb}^{3+}$, or others, $\mathrm{B}^{\prime}$ is a monovalent cation of $\mathrm{Ag}^{+}$or $\mathrm{Na}^{+}$, etc., and $\mathrm{A}$ and $\mathrm{X}$ are the same as the conventional perovskites [7-9].

In particular, $(\mathrm{MA})_{2} \mathrm{AgBiBr}_{6}$ is one kind of promising double perovskite, which has been studied in theoretical work [10]. Yin et al. [11] found that the incorporation of $\mathrm{MA}^{+}$cations into $\mathrm{Cs}_{2} \mathrm{AgBiBr}_{6}$ can effectively modulate its band gap, facilitating more advanced applications. However, to the best of our knowledge, there is only one experimental study of $(\mathrm{MA})_{2} \mathrm{AgBiBr}_{6}$ till now, but its application in photoelectronic devices are still vacant [10]. Different from $(\mathrm{MA})_{2} \mathrm{AgBiBr}_{6}$, $\mathrm{Cs}_{2} \mathrm{AgBiBr}_{6}$ has attracted much more attention, which is another kind of potential double perovskite [7,9,12-15]. Since the organic $\mathrm{MA}^{+}$cation in $(\mathrm{MA})_{2} \mathrm{AgBiBr}_{6}$ is replaced by $\mathrm{Cs}^{+}$, $\mathrm{Cs}_{2} \mathrm{AgBiBr}_{6}$ is supposed to be more stable in harsh environments, such as high-temperature or high-humidity conditions $[16,17]$. To date, most of the $\mathrm{Cs}_{2} \mathrm{AgBiBr}_{6}$ films are fabricated by spin coating methods, in which the crystal quality of the obtained films is shown to be poor, leading to the unsatisfactory photoelectric device performance $[18,19]$. It is therefore important to further explore these high-quality non-toxic double

\footnotetext{
${ }^{1}$ Department of Materials Science and Engineering, City University of Hong Kong, Kowloon 999077, Hong Kong SAR, China

${ }^{2}$ State Key Laboratory of Luminescence and Applications, Changchun Institute of Optics, Fine Mechanics and Physics, Chinese Academy of Sciences, Changchun 130021, China

${ }^{3}$ State Key Laboratory of Terahertz and Millimeter Waves, City University of Hong Kong, Kowloon 999077, Hong Kong SAR, China

${ }^{4}$ Institute for Materials Chemistry and Engineering, Kyushu University, Fukuoka 816-8580, Japan

${ }^{5}$ Key Laboratory of Advanced Materials Processing \& Mold (Ministry of Education), Zhengzhou University, Zhengzhou 450002, China

*Corresponding author (email: johnnyho@cityu.edu.hk)
} 

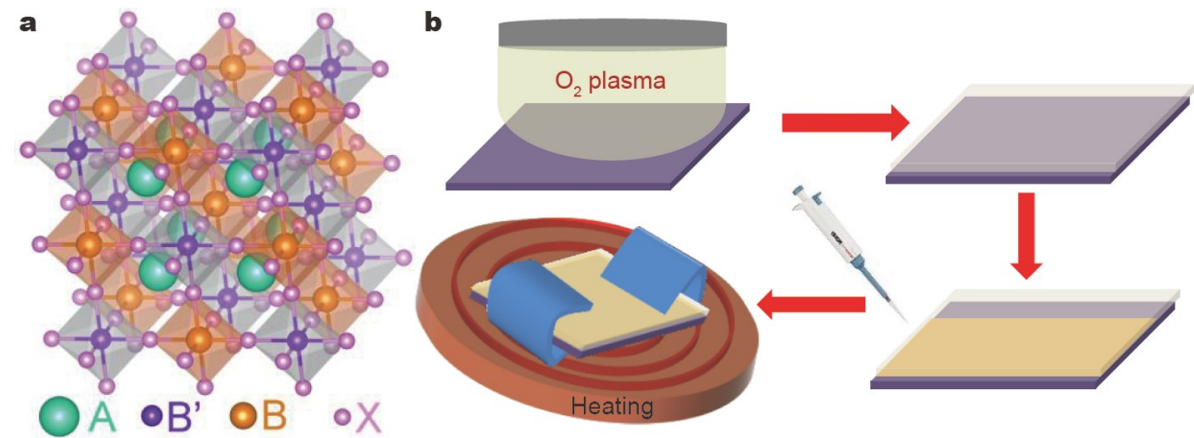

Figure 1 Schematic of the solution-processed space-confined synthesis technique.

perovskite films with enhanced performance and stability.

In this work, we design and develop a facile space-confined synthesis technique to fabricate high-quality double perovskite microplatelets of both $\mathrm{Cs}_{2} \mathrm{AgBiBr}_{6}$ and $(\mathrm{MA})_{2} \mathrm{AgBiBr}_{6}$. The $\mathrm{Cs}_{2} \mathrm{AgBiBr}_{6}$ microplatelets are then configured into simple photodetector devices with detailed characterization of their photodetection properties, followed by the careful comparison against corresponding polycrystalline films (PCFs) synthesized by the conventional spin coating method. It is impressive that both the crystal quality and device performance of the microplatelets are revealed to be much higher than that of PCF. The responsivity of the $\mathrm{Cs}_{2} \mathrm{AgBiBr}_{6}$ microplatelet photodetector is 100 times larger than that of the PCF photodetector while its response speed can be as fast as $145 \mu$ s. Importantly, the microplatelet devices are witnessed with their robust thermal stability. All these results can evidently break down the barriers that hinder the utilization of non-toxic double perovskites, which can also contribute to further development of halide perovskites.

\section{EXPERIMENTAL SECTION}

\section{Synthesis of perovskite precursors}

$\mathrm{CsBr}$ (or $\mathrm{MABr}$ ), $\mathrm{AgBr}$ and $\mathrm{BiBr}_{3}$ at a molar ratio of 2:1:1 were dissolved in dimethylsulfoxide to form a saturated solution. The solution was then stirred at room temperature overnight.

\section{Device fabrication}

The perovskite films and microplatelets were fabricated by a one-step spin-coating method in a nitrogen-filled glovebox, where the oxygen and moisture concentrations were controlled at ppm level. For the fabrication of the microplatelets, the silicon and glass substrates were first ultrasonically washed with acetone, ethanol, and deionized (DI) water. Then, the silicon substrates were treated with mild oxygen plasma to make their surface hydrophilic. After that, one silicon substrate was clipped with another hydrophobic glass substrate. The saturated $\mathrm{Cs}_{2} \mathrm{AgBiBr}_{6}$ or $(\mathrm{MA})_{2} \mathrm{AgBiBr}_{6}$ solution was then dripped on the edges of these two substrates. After the solution got diffused into the gap between the substrates, the clipped substrate stacks were next heated at $90^{\circ} \mathrm{C}$ on a hot plate. During the thermal treatment, the solvent of the solution would evaporate slowly. The microplatelets could be obtained after $48 \mathrm{~h}$. For the $\mathrm{Cs}_{2} \mathrm{AgBiBr}_{6}$ films, $40 \mu \mathrm{L}$ of the precursor solution was spin-coated on the silicon substrate at $3000 \mathrm{r} \mathrm{min}^{-1}$ for $30 \mathrm{~s}$, followed by annealing at $250^{\circ} \mathrm{C}$ for $10 \mathrm{~min}$ on a hot plate. After that, Au electrodes were thermally evaporated onto the samples with the assistance of a shadow mask to complete the device fabrication, where the channel length and width were 15 and $70 \mu \mathrm{m}$, respectively.

\section{Film and device characterization}

$\mathrm{X}$-ray diffraction (XRD) patterns were acquired by the Bruker D2 Phaser X-ray diffractometer with $\mathrm{Cu} \mathrm{Ka}$ radiation. The thickness and surface morphologies of the $\mathrm{Cs}_{2} \mathrm{AgBiBr}_{6}$ microplatelets and films were characterized by atomic force microscopy (AFM, Bruker Dimension Icon) and scanning electron microscopy (SEM, FEI Quanta 450 FEG SEM). High-resolution transmission electron microscopy (HRTEM) image was acquired through an FEI Tecnai G2 F30 transmission electron microscope to study the lattice structure of the microplatelets. Ultravioletvisible (UV-vis) absorption spectra were recorded using a Hitachi UH4150 UV-vis near-infrared (NIR) spectrophotometer. The photoelectrical performance of the photodetectors was studied by a standard electrical probe station and an Agilent 4155C semiconductor analyzer (Agilent Technologies, California, USA). The laser with the wavelength of $450 \mathrm{~nm}$ was used as a light source. The light intensity of the incident irradiation was measured by a power meter (PM400, Thorlabs). For the measurement of the response speed of the photodetector, a low-noise current amplifier (SR570, Stanford Research Systems, USA) along with a digital oscillator (TBS 1102B EDU, Tektronix, USA) was used to obtain the high-resolution currenttime $(I-t)$ curve. Unless otherwise noted, the operating voltage used was fixed at $1.5 \mathrm{~V}$ in this work.

\section{RESULTS AND DISCUSSION}

As depicted in the illustrative schematics in Fig. 1b, this spaceconfined synthesis technique involves an important cleaning step of ultrasonically washing the silicon substrate with acetone, ethanol, and DI water successively, followed by the mild oxygen plasma treatment to improve the hydrophilicity of silicon. Then, the processed silicon substrate is clipped with another hydrophobic glass substrate. Next, the $\mathrm{Cs}_{2} \mathrm{AgBiBr}_{6}$ or $(\mathrm{MA})_{2} \mathrm{AgBiBr}_{6}$ solution is dripped onto the edges of these two substrates. After the solution gets diffused into the gap between the substrates, the clipped substrate stacks are heated on a hot plate, where the solvent of the solution would evaporate slowly to yield the microplatelets subsequently. Unlike the spin-coating method, where a high annealing temperature (over $250^{\circ} \mathrm{C}$ ) is needed to improve the crystallinity of the film, the heating temperature in the space-confined method is as low as $90^{\circ} \mathrm{C}$ to make the solvent evaporate slowly, which is preferred in the fabrication of elec- 
tronic devices.

The XRD pattern of the $\mathrm{Cs}_{2} \mathrm{AgBiBr}_{6}$ microplatelets was measured and shown in Fig. 2a. The peaks of the $\mathrm{Cs}_{2} \mathrm{AgBiBr}_{6}$ microplatelets can be indexed to the simulated XRD pattern (red line), which suggests the pure-phase $\mathrm{Cs}_{2} \mathrm{AgBiBr}_{6}$ is acquired. The $\mathrm{UV}$-vis absorption spectrum of the $\mathrm{Cs}_{2} \mathrm{AgBiBr}_{6}$ microplatelets was also assessed and presented in Fig. $2 \mathrm{~b}$. One can see that its absorption edge is located at $453 \mathrm{~nm}$, suggesting its band gap value of $2.74 \mathrm{eV}$. Moreover, Fig. 2d demonstrates the SEM image of the $\mathrm{Cs}_{2} \mathrm{AgBiBr}_{6}$ microplatelets, in which the lateral dimension of microplatelets is close to submillimeter. The HRTEM image of the microplatelets is also shown in Fig. 2c, which confirms its high crystallinity with the clear lattice spacing fringe of $0.285 \mathrm{~nm}$, corresponding to the (004) plane of the $\mathrm{Cs}_{2} \mathrm{AgBiBr}_{6}$ crystal lattice. The large-area AFM was as well performed on the edge region of the microplatelet. The corresponding image in Fig. $2 \mathrm{e}$ reveals that the microplatelet has a typical thickness of $1.2 \mu \mathrm{m}$. Combined with the AFM topography image in Fig. $2 \mathrm{f}$, the microplatelet has a relatively smooth surface morphology with a root mean square (RMS) roughness as low as $0.31 \mathrm{~nm}$. At the same time, the XRD pattern and absorption spectrum of the $\mathrm{Cs}_{2} \mathrm{AgBiBr}_{6}$ PCF fabricated by spin-coating are depicted in
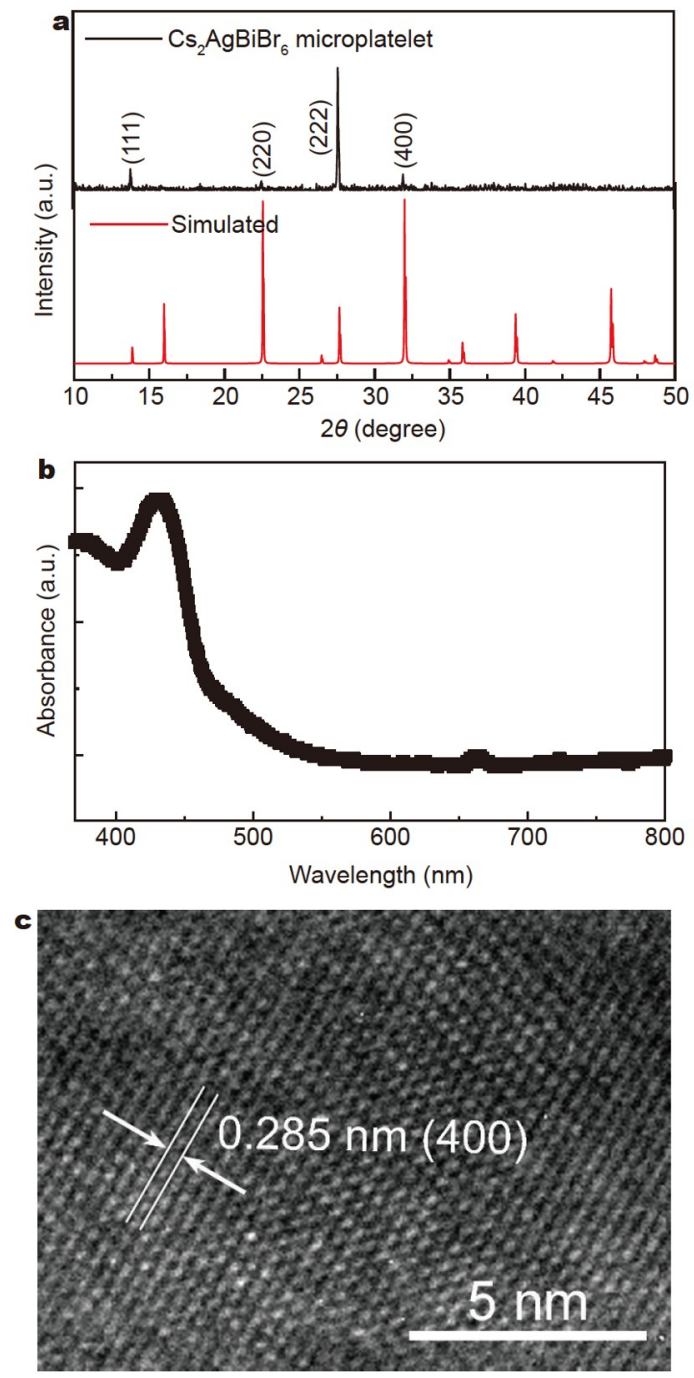

Figs S1 and S2. The XRD peaks are consistent with the simulated ones, but the intensity is obviously much weaker than those of the $\mathrm{Cs}_{2} \mathrm{AgBiBr}_{6}$ microplatelets. The absorption edge of the $\mathrm{Cs}_{2} \mathrm{AgBiBr}_{6} \mathrm{PCF}$ is found to locate at $451 \mathrm{~nm}$; therefore, the band gap of $2.75 \mathrm{eV}$ is determined. Besides, it is witnessed that the $\mathrm{Cs}_{2} \mathrm{AgBiBr}_{6}$ PCF exhibits obvious crystal grains in the SEM image in Fig. S3. The corresponding RMS surface roughness is measured to be $13.7 \mathrm{~nm}$ based on the AFM image acquired in Fig. S4. This surface roughness value is much larger than that of the microplatelets $(0.31 \mathrm{~nm})$. These results can evidently illustrate that the quality of the $\mathrm{Cs}_{2} \mathrm{AgBiBr}_{6}$ microplatelets fabricated by the space-confined technique is much better than that attained by the conventional spin coating method.

To characterize and compare the photodetection properties of the $\mathrm{Cs}_{2} \mathrm{AgBiBr}_{6}$ microplatelets and PCF, their photodetectors were configured and studied. The SEM image of the device structure is shown in the inset of Fig. 3b, where the square shape $\mathrm{Au}$ electrodes are deposited by thermal evaporation with the assistance of a shadow mask and the channel width and length are 70 and $15 \mu \mathrm{m}$, respectively. The photocurrent-voltage (I-V) curves of the $\mathrm{Cs}_{2} \mathrm{AgBiBr}_{6}$ microplatelets under different light intensities are shown in Fig. S5, where the wavelength of the

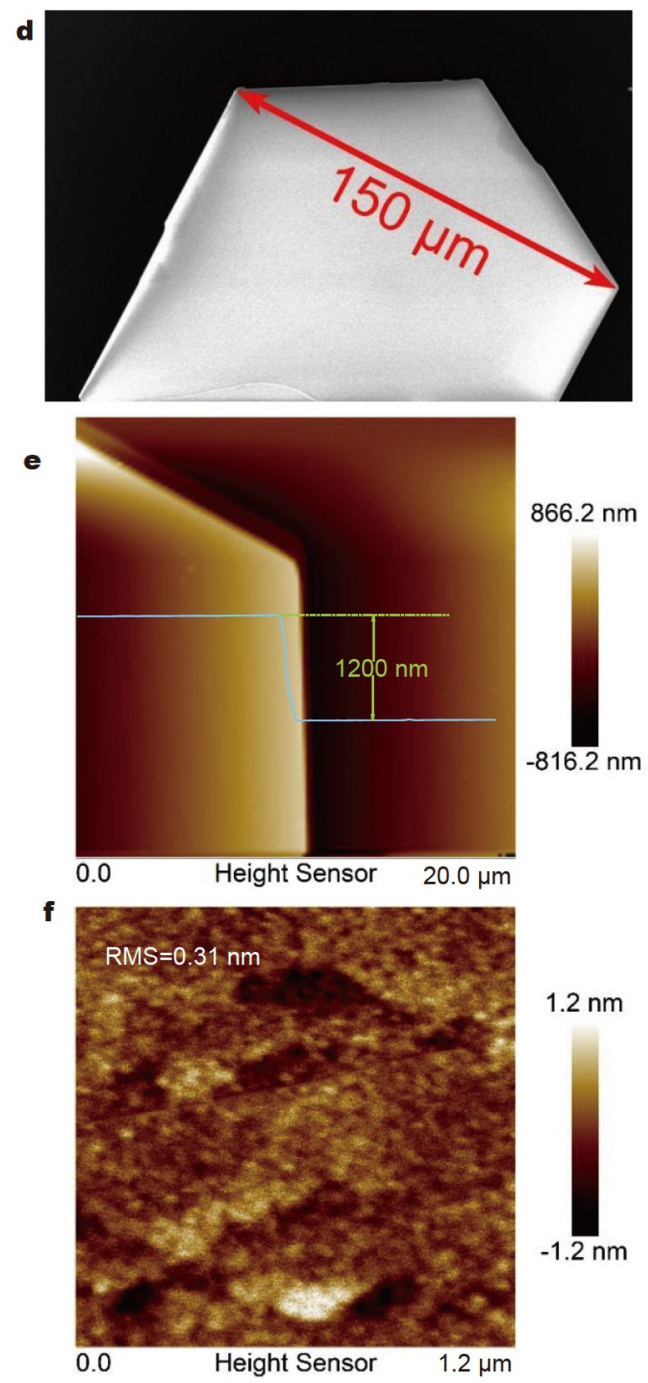

Figure 2 (a) XRD pattern and the simulated spectrum, (b) absorption spectrum, (c) HRTEM image, (d) SEM image, (e) large-area AFM image, and (f) closeup AFM image of the obtained $\mathrm{Cs}_{2} \mathrm{AgBiBr}_{6}$ microplatelets. 

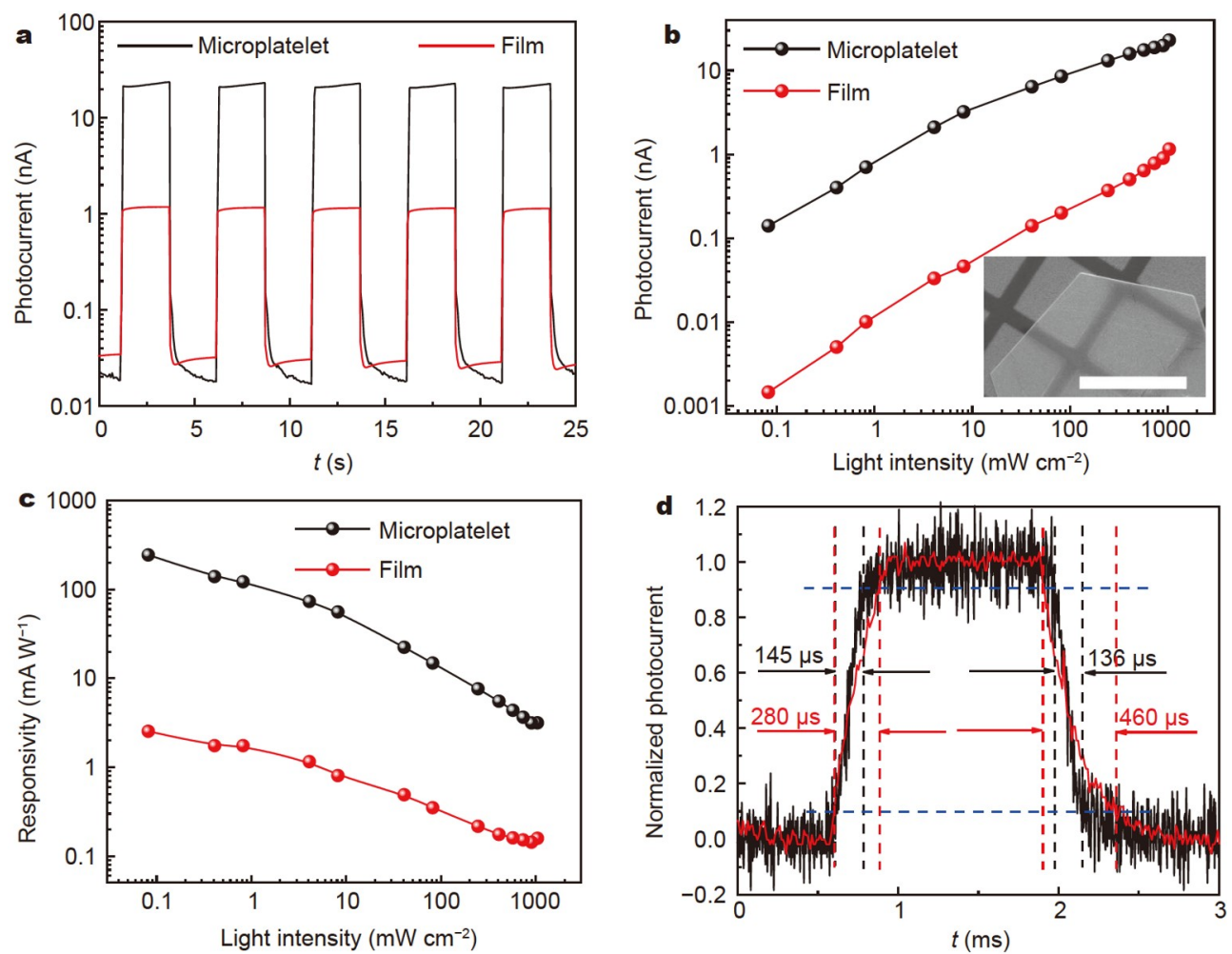

Figure 3 (a) I-t curves under chopped laser, (b) photocurrent as a function of the light intensity, where the inset shows the SEM image of the as-prepared device, and the scale bar is $100 \mu \mathrm{m}$, (c) responsivity as a function of the light intensity of the $\mathrm{Cs}_{2} \mathrm{AgBiBr}_{6}$ microplatelets- and film-based photodetectors. (d) High-resolution I- $t$ curve of the $\mathrm{Cs}_{2} \mathrm{AgBiBr}_{6}$ microplatelets-based photodetector.

laser used is $450 \mathrm{~nm}$. All these $I-V$ curves are linear, suggesting the nearly ohmic contact properties, which is benefitial for collecting the photogenerated carriers effectively. The on/off current ratio of the microplatelets-based photodetector can then be determined to be $2.8 \times 10^{3}$. Fig. 3a displays the $I$ - $t$ curves of the microplatelets- and PCF-based photodetectors under $1000 \mathrm{~mW} \mathrm{~cm}^{-2}$ chopped illumination. It is obvious that the switching on-off cycles of the photodetectors are stable, while the photocurrent of the microplatelet device is about 20 times larger than that of the PCF. Besides, the dark current of the microplatelet device is still smaller than that of the PCF. Accordingly, the enhanced photocurrent and reduced dark current together would lead to a high on/off current ratio of the $\mathrm{Cs}_{2} \mathrm{AgBiBr}_{6}$ microplatelets-based photodetector, which is preferred for high-performance optoelectronic devices. The photocurrents under different light intensities are shown in Fig. 3b. The photocurrents of both the microplatelet and PCF devices show almost the linear relationship with the light intensities, which is favorable for the broadband photodetector applications [20]. In addition, the responsivity $(R)$ of the photodetector is a crucial parameter that can be calculated through the equation: $R=\frac{I_{\mathrm{p}}}{\Phi S}$, where $I_{\mathrm{p}}$ is the photocurrent, $\Phi$ is the light intensity, and $S$ is the active area of the photodetector [21]. As shown in Fig. 3c, the largest $R$ of the microplatelet device is as large as $245 \mathrm{~mA} \mathrm{~W}^{-1}$, which is about two orders of magnitude larger than that of PCF $\left(2.5 \mathrm{~mA} \mathrm{~W}^{-1}\right)$. The superior responsivity of the $\mathrm{Cs}_{2} \mathrm{AgBiBr}_{6}$ microplatelet device must benefit from its high quality of the obtained film. Furthermore, the detectivity $\left(D^{*}\right)$ and external quantum efficiency (EQE) are also important parameters of photodetectors, which can be defined as $D^{*}=$
$R S^{1 / 2} /\left(2 e I_{\mathrm{dark}}\right)^{1 / 2}$ and $\mathrm{EQE}=h c R / e \lambda\left(e, I_{\mathrm{dark}}, h, c\right.$, and $\lambda$ represent the electronic charge, dark current, Planck's constant, velocity of the incident light, and wavelength of the incident light, respectively) [22]. In this case, the $D^{*}$ and $\mathrm{EQE}$ of the photodetectors were calculated and depicted in Fig. S6. As predicted, the $D^{*}$ and $\mathrm{EQE}$ of the $\mathrm{Cs}_{2} \mathrm{AgBiBr}_{6}$ microplatelet device are much larger than those of the PCF device, where the largest $D^{*}$ and EQE are $1.3 \times 10^{11}$ Jones and $67.6 \%$, respectively. More importantly, the response speed is also an essential parameter for the performance evaluation of photodetectors, especially for high-frequency devices. As presented in Fig. 3d, the high-resolution I-t curves of the microplatelets and films were measured to characterize the response speed, where the rise time and decay time were defined as the times required for current to increase from $10 \%$ to $90 \%$ and decrease from $90 \%$ to $10 \%$, respectively. The rise and decay times of the $\mathrm{Cs}_{2} \mathrm{AgBiBr}_{6}$ microplatelets-based photodetectors are determined to be as fast as 145 and $136 \mu$ s, respectively, which is superior to those of the films. As compared with other double perovskite-based photodetectors summarized in Table 1 , it is clear that the responsivity and especially the response speed of our pure $\mathrm{Cs}_{2} \mathrm{AgBiBr}_{6}$-based photodetectors are superior to most of the composite structures-based devices. This excellent performance can be attributed to the good crystallinity of the microplatelets. Consequently, the space-charge-limited current (SCLC) measurement was performed to compare the trap densities and carrier mobilities of the microplatelets and films. As shown in Fig. S7, the trap filling limit voltages $\left(V_{\mathrm{TFL}}\right)$ are identified and labeled. The trap densities and carrier mobilities can then be calculated based on Mott-Gurney law with the equation of $n_{\mathrm{t}}=2 \varepsilon \varepsilon_{0} V_{\mathrm{TFL}} / e L^{2}$, where $n_{\mathrm{t}}$ is the trap density, $\varepsilon$ is the relative dielectric constant $(=5.8), \varepsilon_{0}$ is the vacuum permittivity, 
Table 1 Comparison of various figure of merits of double perovskite-based photodetectors

\begin{tabular}{|c|c|c|c|c|c|}
\hline Structure & EQE (\%) & $R\left(\mathrm{~mA} \mathrm{~W}^{-1}\right)$ & $D^{*}$ (Jones) & Response time (ms) & References \\
\hline $\mathrm{SnO}_{2} / \mathrm{Cs}_{2} \mathrm{AgBiBr}_{6} / \mathrm{Au}$ & 40 & 110 & $2.1 \times 10^{10}$ & 2 & {$[26]$} \\
\hline $\mathrm{SnO}_{2} / \mathrm{Cs}_{2} \mathrm{AgBiBr}_{6} / \mathrm{TFB}^{\mathrm{a}} / \mathrm{Au}$ & 35 & 140 & $3.3 \times 10^{12}$ & 0.000017 & {$[27]$} \\
\hline In/GaN-Cs $2 \mathrm{AgBiBr}_{6} / \mathrm{Ag}$ & - & 1460 & $9.4 \times 10^{12}$ & 3.5 & [28] \\
\hline $\mathrm{Au} / \mathrm{Cs}_{2} \mathrm{AgBiBr}_{6} / \mathrm{Au}$ & 2146 & 7010 & $5.66 \times 10^{11}$ & 5.77 & {$[29]$} \\
\hline F-doped $\mathrm{SnO}_{2} / \mathrm{TiO}_{2} / \mathrm{Cs}_{2} \mathrm{AgBiBr}_{6} / \mathrm{CuSCN} / \mathrm{Au}$ & - & 340 & $1.03 \times 10^{13}$ & 28.75 & {$[30]$} \\
\hline $\mathrm{Au} / \mathrm{Cs}_{2} \mathrm{AgInCl}_{6} / \mathrm{Au}$ & - & $\sim 32$ & $10^{12}$ & 0.97 & {$[31]$} \\
\hline $\mathrm{Au} / \mathrm{Cs}_{2} \mathrm{AgBiCl}_{6} / \mathrm{FTO}$ & - & $\sim 10$ & $10^{12}$ & - & {$[32]$} \\
\hline $\mathrm{Al} / \mathrm{Cs}_{4} \mathrm{CuSb}_{2} \mathrm{Cl}_{12}$-carbon matrix/Al & - & $\sim 0.0017$ & $10^{8}$ & 120 & [33] \\
\hline $\mathrm{Au} / \mathrm{Cs}_{2} \mathrm{AgBiBr}_{6} / \mathrm{Au}$ & 67.5 & 245 & $1.3 \times 10^{11}$ & 0.145 & This work \\
\hline
\end{tabular}

a) TFB: poly[9,9-dioctyl uorenyl-2,7-diyl)-co-(4,4'-(N-(4-sec-butylphenyl) diphenylamine)]

and $L$ is the length of the device channel [23-25]. The calaulated values are listed in Table S1. One can see that the carrier mobility of $\mathrm{Cs}_{2} \mathrm{AgBiBr}_{6}$ microplatelets is higher than that of the films while the trap density of the microplatelets is much lower. These SCLC measurement results confirm again the superior quality of the microplatelets.

Nonetheless, the stability of the perovskite-based photodetectors is still a weakness for practical utilization. Apart from the moisture stability, the thermal stability of perovskites especially the organic-inorganic hybrid films is still far from satisfactory. Accordingly, the thermal stability of the $\mathrm{Cs}_{2} \mathrm{AgBiBr}_{6}$ microplatelets-based photodetector was carefully studied. As shown in Fig. 4a, the device performance is first measured at room temperature $\left(25^{\circ} \mathrm{C}\right)$ in ambient environment $(70 \%$ relative humidity) and then the temperature is gradually increased to $160^{\circ} \mathrm{C}$, staying for $5 \mathrm{~min}$ at every measuring point. Afterwards, the temperature cools down to room temperature, where the intensity of the incident laser is set at $1.5 \mathrm{~W} \mathrm{~cm}^{-2}$ for the entire measurement. The dark current, photocurrent and on/off current ratio of the device at different temperatures are extracted and plotted in Fig. 4b. It is observed that the dark current increases from 0.07 to $39 \mathrm{nA}$ and the photocurrent increases from 40 to $370 \mathrm{nA}$, as the temperature increases from room temperature to $160^{\circ} \mathrm{C}$. It is because that the carriers are easier to be motivated due to their increased kinetic energy at elevated temperatures. Nevertheless, the dark current is much smaller than the photocurrent, explaining the reason that the carriers in the device under dark are much fewer than the case under the illumination; therefore, the dark current will be more sensitive to the temperature-induced fluctuation of the carriers. In addition, as the temperature increases, the ionic migration is accelerated, which will also contribute to the increase of the dark current [34]. Accordingly, the dark current increases at a rate faster than that of the photocurrent, so the on/off current ratio decreases with increasing temperature. Importantly, after the temperature cooling back to room temperature, the photocurrent can restore its initial value and the dark current even becomes slightly smaller after the high-temperature heating. In this case, the excellent thermal stability of the $\mathrm{Cs}_{2} \mathrm{AgBiBr}_{6}$ microplatelets is confirmed, which makes it more promising for the applications in high-temperature environments.

Besides the all-inorganic $\mathrm{Cs}_{2} \mathrm{AgBiBr}_{6}$, this facile space-confined synthesis technique can also be applied to the organicinorganic double perovskite of $\mathrm{MA}_{2} \mathrm{AgBiBr}_{6}$. As demonstrated in the SEM image in Fig. S8a, the obtained $\mathrm{MA}_{2} \mathrm{AgBiBr}_{6}$ microplatelet has a typical size of several hundreds of micrometers. Its nominal thickness and RMS surface roughness are about $802 \mathrm{~nm}$ and as low as $1.24 \mathrm{~nm}$, respectively, directly reading from the large-area AFM images in Fig. S8b, c. Based on the absorption spectrum, the microplatelets have a bandgap of $2.61 \mathrm{eV}$ (Fig. S8d), indicating the successful synthesis of $\mathrm{MA}_{2} \mathrm{AgBiBr}_{6}$ microplatelets. The $\mathrm{MA}_{2} \mathrm{AgBiBr}_{6}$ microplatelets-based photodetector was also configured and characterized, where a laser with a wavelength of $450 \mathrm{~nm}$ was used. The SEM image of the device is also shown in Fig. S9. The $I-V$ curves under the illumination with different light intensities are depicted in Fig. S10a, which shows a remarkable enhancement as the light intensity increases, suggesting the typical light-sensitive properties. The $I$ -
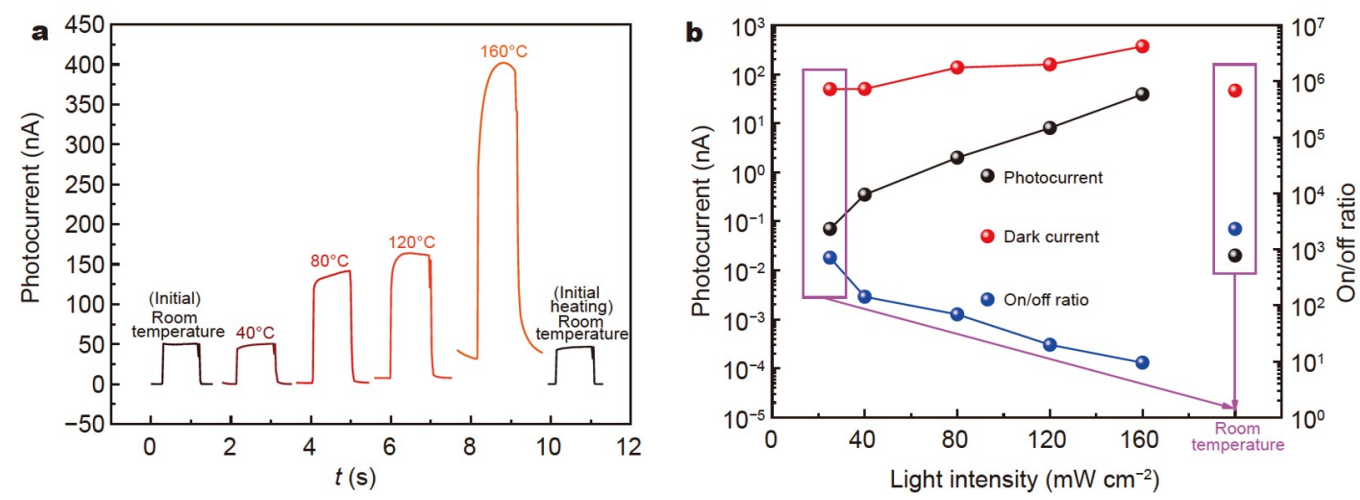

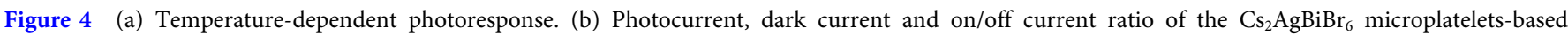
photodetector as a function of the working temperature. 
$t$ curves under chopped light with the intensity of $600 \mathrm{~mW} \mathrm{~cm}^{-2}$ are shown in Fig. S10b, indicating the good switching repeatability. The on-off current ratio is determined to be 281 . The responsivity, $D^{*}$, and EQE under varied light intensities were also calculated and demonstrated in Fig. S10c, d, where the largest values are $58 \mathrm{~mA} \mathrm{~W}^{-1}, 2.9 \times 10^{10}$, and $16 \%$, respectively. One can see that the performance of the $\mathrm{MA}_{2} \mathrm{AgBiBr}_{6}$ microplatelets-based photodetector is not as good as that of $\mathrm{Cs}_{2} \mathrm{AgBiBr}_{6}$. It may be because that the large MA molecules can lead to lattice distortion of the perovskites, which can lead to more trap densities [10]. Besides, the ionic conductivity of $\mathrm{MA}_{2} \mathrm{AgBiBr}_{6}$ is also proved to be smaller. All these features of $\mathrm{MA}_{2} \mathrm{AgBiBr}_{6}$ will result in its relatively poor photoelectric properties than that of $\mathrm{Cs}_{2} \mathrm{AgBiBr}_{6}$.

\section{CONCLUSIONS}

In conclusion, high-quality $\mathrm{Cs}_{2} \mathrm{AgBiBr}_{6}$ microplatelets were synthesized by the solution processed space-confined synthesis technique. Attributed to the high-quality films fabricated by this facile method, the photodetection performance of $\mathrm{Cs}_{2} \mathrm{AgBiBr}_{6}$ microplatelets is improved significantly as compared with the films fabricated by the conventional spin-coating method. The responsivity of the microplatelets-based photodetector reaches $245 \mathrm{~mA} \mathrm{~W}^{-1}$, which is even two orders of magnitude larger than that of PCF. The response speed is as fast as $145 \mu$ s. Importantly, the thermal stability of microplatelets is also proved, which can maintain its initial performance after heating to $160^{\circ} \mathrm{C}$ in ambient environment. Notably, the organic-inorganic $\mathrm{MA}_{2} \mathrm{AgBiBr}_{6}$ microplatelets can also be synthesized by this method, which suggests its universality to fabricate halide perovskite microplatelets. All these findings not only demonstrate the feasibility of using the solution-processed space-confined technique to readily achieve high-quality double perovskites but also enable the lead-free double perovskite alternatives of $\mathrm{Cs}_{2} \mathrm{AgBiBr}_{6}$ for high-performance photodetectors and potentially other optoelectronic devices.

\section{Received 16 September 2021; accepted 16 November 2021;} published online 20 December 2021

1 Wang HP, Li S, Liu X, et al. Low-dimensional metal halide perovskite photodetectors. Adv Mater, 2021, 33: 2003309

2 Younis A, Lin CH, Guan X, et al. Halide perovskites: A new era of solution-processed electronics. Adv Mater, 2021, 33: 2005000

3 Wang $\mathrm{K}, \mathrm{Wu} \mathrm{C}, \mathrm{Hou} \mathrm{Y}$, et al. Isothermally crystallized perovskites at room-temperature. Energy Environ Sci, 2020, 13: 3412-3422

4 Xian Y, Yin H, Bao Y, et al. Engineered electronic structure and carrier dynamics in emerging $\mathrm{Cs}_{2} \mathrm{Ag}_{x} \mathrm{Na}_{1-x} \mathrm{FeCl}_{6}$ perovskite single crystals. J Phys Chem Lett, 2020, 11: 9535-9542

5 Kang C, Rao H, Fang Y, et al. Antioxidative stannous oxalate derived lead-free stable $\mathrm{CsSnX}_{3}(\mathrm{X}=\mathrm{Cl}, \mathrm{Br}$, and I) perovskite nanocrystals. Angew Chem Int Ed, 2021, 60: 660-665

6 Wang L, Su J, Guo Y, et al. $97.3 \% \mathrm{~Pb}$-reduced $\mathrm{CsPb}_{1-x} \mathrm{Ge}_{x} \mathrm{Br}_{3}$ perovskite with enhanced phase stability and photovoltaic performance through surface Cu doping. J Phys Chem Lett, 2021, 12: 1098-1103

7 McClure ET, Ball MR, Windl W, et al. $\mathrm{Cs}_{2} \operatorname{AgBiX}_{6}(\mathrm{X}=\mathrm{Br}, \mathrm{Cl})$ : New visible light absorbing, lead-free halide perovskite semiconductors. Chem Mater, 2016, 28: 1348-1354

8 Slavney $\mathrm{AH}, \mathrm{Hu} \mathrm{T}$, Lindenberg $\mathrm{AM}$, et al. A bismuth-halide double perovskite with long carrier recombination lifetime for photovoltaic applications. J Am Chem Soc, 2016, 138: 2138-2141

9 Ning W, Wang F, Wu B, et al. Long electron-hole diffusion length in high-quality lead-free double perovskite films. Adv Mater, 2018, 30: 1706246
10 Wei F, Deng Z, Sun S, et al. Synthesis and properties of a lead-free hybrid double perovskite: $\left(\mathrm{CH}_{3} \mathrm{NH}_{3}\right)_{2} \mathrm{AgBiBr}_{6}$. Chem Mater, 2017, 29 : 1089-1094

11 Yin R, Yu G, Cong WY, et al. Modulation effect generated by A cations in hybrid $\mathrm{A}_{2} \mathrm{BB}^{\prime} \mathrm{X}_{6}$ double halogen perovskite materials. ACS Appl Mater Interfaces, 2020, 12: 44798-44804

12 Kentsch R, Scholz M, Horn J, et al. Exciton dynamics and electronphonon coupling affect the photovoltaic performance of the $\mathrm{Cs}_{2} \mathrm{AgBiBr}_{6}$ double perovskite. J Phys Chem C, 2018, 122: 25940-25947

13 Yang $\mathrm{X}$, Chen $\mathrm{Y}$, Liu $\mathrm{P}$, et al. Simultaneous power conversion efficiency and stability enhancement of $\mathrm{Cs}_{2} \mathrm{AgBiBr}_{6}$ lead-free inorganic perovskite solar cell through adopting a multifunctional dye interlayer. Adv Funct Mater, 2020, 30: 2001557

14 Zhang W, Gong Z, Pan S, et al. Growth and photodetection properties of $\mathrm{Cs}_{2} \mathrm{AgBiBr}_{6}$ crystals with large flat $\left(\begin{array}{lll}1 & 1 & 1\end{array}\right)$ plane grown from the solution by adding toluene. J Cryst Growth, 2020, 552: 125922

15 Pistor P, Meyns M, Guc M, et al. Advanced Raman spectroscopy of $\mathrm{Cs}_{2} \mathrm{AgBiBr}_{6}$ double perovskites and identification of $\mathrm{Cs}_{3} \mathrm{Bi}_{2} \mathrm{Br}_{9}$ secondary phases. Scripta Mater, 2020, 184: 24-29

16 Li Y, Shi Z, Lei L, et al. Highly stable perovskite photodetector based on vapor-processed micrometer-scale $\mathrm{CsPbBr}_{3}$ microplatelets. Chem Mater, 2018, 30: 6744-6755

17 Li S, Shi Z, Zhang F, et al. Ultrastable lead-free double perovskite warm-white light-emitting devices with a lifetime above 1000 hours. ACS Appl Mater Interfaces, 2020, 12: 46330-46339

18 Greul E, Petrus ML, Binek A, et al. Highly stable, phase pure $\mathrm{Cs}_{2} \mathrm{AgBiBr}_{6}$ double perovskite thin films for optoelectronic applications. J Mater Chem A, 2017, 5: 19972-19981

19 Gao W, Ran C, Xi J, et al. High-quality $\mathrm{Cs}_{2} \mathrm{AgBiBr}_{6}$ double perovskite film for lead-free inverted planar heterojunction solar cells with $2.2 \%$ efficiency. ChemPhysChem, 2018, 19: 1696-1700

20 Deka N, Chakraborty P, Patra DC, et al. Self-powered broadband photodetection using $\mathrm{PbS}$ decorated $\mathrm{ZnO}$ nanorods/reduced graphene oxide junction. Mater Sci Semicond Proc, 2020, 118: 105165

21 Lai Z, Dong R, Zhu Q, et al. Bication-mediated quasi-2D halide perovskites for high-performance flexible photodetectors: From Ruddlesden-Popper type to Dion-Jacobson type. ACS Appl Mater Interfaces, 2020, 12: 39567-39577

22 Meng Y, Lan C, Li F, et al. Direct vapor-liquid-solid synthesis of allinorganic perovskite nanowires for high-performance electronics and optoelectronics. ACS Nano, 2019, 13: 6060-6070

23 Duijnstee EA, Ball JM, Le Corre VM, et al. Toward understanding space-charge limited current measurements on metal halide perovskites. ACS Energy Lett, 2020, 5: 376-384

24 Feng J, Yan X, Liu Y, et al. Crystallographically aligned perovskite structures for high-performance polarization-sensitive photodetectors. Adv Mater, 2017, 29: 1605993

25 Filip MR, Hillman S, Haghighirad AA, et al. Band gaps of the lead-free halide double perovskites $\mathrm{Cs}_{2} \mathrm{BiAgCl}_{6}$ and $\mathrm{Cs}_{2} \mathrm{BiAgBr}_{6}$ from theory and experiment. J Phys Chem Lett, 2016, 7: 2579-2585

26 Wu C, Du B, Luo W, et al. Highly efficient and stable self-powered ultraviolet and deep-blue photodetector based on $\mathrm{Cs}_{2} \mathrm{AgBiBr}_{6} / \mathrm{SnO}_{2}$ heterojunction. Adv Opt Mater, 2018, 6: 1800811

27 Yang J, Bao C, Ning W, et al. Stable, high-sensitivity and fast-response photodetectors based on lead-free $\mathrm{Cs}_{2} \mathrm{AgBiBr}_{6}$ double perovskite films. Adv Opt Mater, 2019, 7: 1801732

28 Li Y, Shi Z, Lei L, et al. Ultrastable lead-free double perovskite photodetectors with imaging capability. Adv Mater Interfaces, 2019, 6: 1900188

29 Lei LZ, Shi ZF, Li Y, et al. High-efficiency and air-stable photodetectors based on lead-free double perovskite $\mathrm{Cs}_{2} \mathrm{AgBiBr}_{6}$ thin films. J Mater Chem C, 2018, 6: 7982-7988

30 Yan G, Ji Z, Li Z, et al. All-inorganic $\mathrm{Cs}_{2} \mathrm{AgBiBr}_{6} / \mathrm{CuSCN}$-based photodetectors for weak light imaging. Sci China Mater, 2021, 64: 198-208

31 Luo J, Li S, Wu H, et al. $\mathrm{Cs}_{2} \mathrm{AgInCl}_{6}$ double perovskite single crystals: Parity forbidden transitions and their application for sensitive and fast UV photodetectors. ACS Photonics, 2018, 5: 398-405

32 Wang $\mathrm{M}$, Zeng $\mathrm{P}$, Wang $\mathrm{Z}$, et al. Vapor-deposited $\mathrm{Cs}_{2} \mathrm{AgBiCl}_{6}$ double perovskite films toward highly selective and stable ultraviolet photo- 
detector. Adv Sci, 2020, 7: 1903662

33 Jayasankar PM, Pathak AK, Madhusudanan SP, et al. Double perovskite $\mathrm{Cs}_{4} \mathrm{CuSb}_{2} \mathrm{Cl}_{12}$ microcrystalline device for cost effective photodetector applications. Mater Lett, 2020, 263: 127200

34 Yuan Y, Wang Q, Shao Y, et al. Electric-field-driven reversible conversion between methylammonium lead triiodide perovskites and lead iodide at elevated temperatures. Adv Energy Mater, 2016, 6: 1501803

Acknowledgements This work was financially supported by the Research Fellow Scheme (RFS2021-1S04), the Theme-based Research (T42-103/16-N) of the Research Grants Council of Hong Kong SAR, China, and Foshan Innovative and Entrepreneurial Research Team Program (2018IT100031).

Author contributions Lai $\mathrm{Z}$ and Ho J conceived the idea and wrote the manuscript. Lai Z, Wang F and Meng Y performed the device fabrication and characterizations. Bu X, Kang X, Quan Q, Wang W, Yip SP and Liu C participated in the discussion on experimental results and advised on data analysis. Ho J directed this project.

Conflict of interest The authors declare that they have no conflict of interest.

Supplementary information Supporting data are available in the online version of the paper.

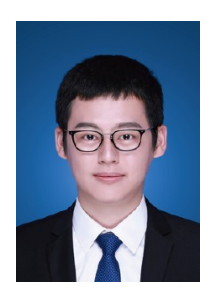

Zhengxun Lai received his BSc and MS degrees from Tianjin University in 2016 and 2019. Currently, he is a $\mathrm{PhD}$ candidate at the City University of Hong Kong. His research interests are focused on the halide perovskites electronic and photoelectric devices.

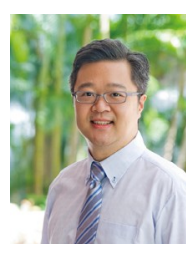

Johnny C. Ho is a professor of materials science and engineering at the City University of Hong Kong. He received his BS degree in chemical engineering in 2002, and his MS and $\mathrm{PhD}$ degrees in materials science and engineering from the University of California, Berkeley, in 2005 and 2009, respectively. From 2009 to 2010, he was a postdoctoral research fellow in the Nanoscale Synthesis and Characterization Group at Lawrence Livermore $\mathrm{Na}$ tional Laboratory.

\section{溶液法制备无铅双钻钛矿纳米片提升光响应和热稳} 定性

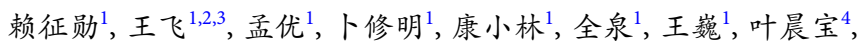
刘春太 $太^{5}$, 何颂贤 $1,3,4^{*}$

摘要 无铅双钙钛矿由于具有较好的稳定性和无毒的特点吸引了很多 学者的目光, 有希望成为下一代光伏和光电子材料. 然而, 目前其光电 器件性能并不理想. 我们报道了一个简单的溶液法用于制备无机双钲 钛矿 $\mathrm{Cs}_{2} \mathrm{AgBiBr}_{6}$ 和 $\mathrm{MA}_{2} \mathrm{AgBiBr}_{6}$ 微米片. 与传统的溶液旋涂法相比, 这种 方法得到的 $\mathrm{Cs}_{2} \mathrm{AgBiBr}_{6}$ 和 $\mathrm{MA}_{2} \mathrm{AgBiBr}_{6}$ 微米片具有很好的结晶性. 将它 们做成光电探测器后, 其响应度达到了 $245 \mathrm{~mA} \mathrm{~W}^{-1}$, 比旋涂法制备的 器件高出两个量级, 且响应时间为 $145 \mu \mathrm{s}$. 热稳定性研究表明, 将 $\mathrm{Cs}_{2} \mathrm{Ag}$ $\mathrm{BiBr}_{6}$ 器件在空气中加热到 $160^{\circ} \mathrm{C}$ 再回到室温, 其光电响应并没有受到影 响. 这些结果表明, 溶液法制备无铅双钲钛矿具有更广阔的应用前景. 